\title{
Um Modelo para Análise Socioeconômica da Criminalidade no Município de Aracaju
}

\author{
Alan Alexander Mendes Lemos \\ Professor do Departamento de Engenharia Agronômica \\ da Universidade Federal de Sergipe \\ Eurílio Pereira Santos Filho \\ Professor do Departamento de Economia da Universidade Federal \\ de Sergipe e da Universidade Tiradentes /SE \\ Marco Antonio Jorge \\ Professor do Departamento de Economia da Universidade Tiradentes/SE
}

\begin{abstract}
RESUMO
Este trabalho tem por objetivo investigar as razões socioeconômicas da criminalidade em Aracaju, a partir de fontes primárias e secundárias de informação. Para tanto, parte-se de uma análise teórica, na qual foram identificadas quatro hipóteses explicativas para a criminalidade: (i) ato racional deliberado; (ii) relacionada com o ciclo econômico; (iii) decorrente da maior desigualdade social existente na economia contemporânea e; (iv) não diretamente relacionada com variáveis socioeconômicas. A seção seguinte descreve a metodologia empregada para a construção do banco de dados e para a análise por meio de regressão do tipo stepwise. Na última seção são apresentados os resultados: o modelo explica $90 \%$ do comportamento dos crimes contra o patrimônio, e as variáveis responsáveis por tal comportamento são: a concentração de renda, características da infra-estrutura existente nos bairros, a baixa densidade demográfica e a menor participação dos jovens no total da população.
\end{abstract}

\section{PALAVRAS-CHAVE}

criminalidade, regressão stepwise, Aracaju

ABSTRACT

This paper aims to investigate the socioeconomic reasons of criminality in Aracaju/SE, using primary and secondary sources of information. Beginning with a theoretical analysis, we identified four hyphotesis to the criminality which are: (i) a deliberated rational action; (ii) related to the economic cycle; (iii) consequence of the growing social inequality in the contemporary economy and (iv) not directly related to the

socioeconomic reasons. The next section describes the methodology employed to construct the data-

base and for analysis through stepwise regression. The results are presented in the last section: our model explains $90 \%$ of the property crime behavior, mainly due: income inequality, existing characteristics of infrastructure in the city districts, low demographic density and low rate of youths' participation in the whole population.

KEY WORDS criminality, stepwise regression, Aracaju

JEL Classification

D6I, K42

EST. ECON., SÃO PAULO, V. 35, N. 3, P. 569-594, JULHO-SETEMBRO 2005 


\section{INTRODUÇÃO}

A criminalidade, aqui entendida como violação às normas legalmente estabelecidas, vem assumindo níveis alarmantes em nosso país. Para se ter uma idéia da dimensão deste fenômeno, basta atentar para o fato de que durante a Guerra do Vietnã (19591975) houve cerca de 43.700 baixas anuais, de ambos os lados. Pois bem, no Brasil, somente no ano 2002, cerca de 38.000 indivíduos foram assassinados. (http:// www.mj.gov.br/senasp). ${ }^{1}$ Obviamente, isto acarreta custos sociais, correntemente estimados em cerca de 10\% do PIB brasileiro. (ARAÚJO JR. \& FAJNZYLBER, 2001, p. 334). Tais custos são de três ordens:

i. despesas públicas direta e indiretamente alocadas para a prevenção e o combate ao crime;

ii. gastos efetuados pelo setor privado diretamente na aquisição de equipamentos de "segurança", além das perdas patrimoniais decorrentes de atos ilícitos; e

iii. custos intangíveis ou valores que deixam de ser recebidos/produzidos pela sociedade em função do medo da violência. (KAHN, 2000).

Assim, faz-se mister empreender políticas públicas de prevenção e combate à criminalidade, o que, por sua vez, demanda uma análise apurada de suas causas. Este é precisamente o objetivo principal deste trabalho: identificar as principais causas da criminalidade em Aracaju, a partir de um diagnóstico teórico e de fontes primárias e secundárias de informação.

Como objetivos específicos podemos citar:

a. diferenciar a análise do que tem sido comumente feito em estudos do gênero, que limitam a fundamentação teórica do problema a uma questão de análise custo-benefício, o que, a nosso ver, é um enfoque útil, porém restrito;

b. empreender uma pesquisa de campo destinada a gerar dados primários para o estudo do fenômeno; e

c. elaborar um diagnóstico acerca das principais razôes socioeconômicas da criminalidade no município de Aracaju/SE² por meio da utilização de técnicas econométricas.

1 O número de homicídios dolosos registrados foi de 37.949, mas não inclui os dados dos Estados de Pernambuco e Piauí, que estão revisando suas informações.

2 Foram registrados 216 homicídios dolosos no município de Aracaju no ano 2000, o que representa uma taxa de 46,8 por cem mil habitantes. Nas cidades do Rio de Janeiro e de São Paulo esta taxa era de 37,8 e 51,1 , respectivamente, naquele ano. Ou seja, Aracaju tinha uma taxa superior à do Rio de Janeiro. No ano seguinte, o número de homicídios dolosos caiu para 120 , o que representa uma taxa de 25,6 por cem mil habitantes. A despeito dessa queda expressiva, Aracaju foi a quarta capital mais violenta da Regiáo Nordeste em 2001. (http://www.mj.gov.Br/senasp, jul/2003). 
Para tanto, o trabalho está estruturado em três seções além desta introdução: na primeira são discutidas quatro hipóteses para a explicação da criminalidade, sob a ótica da ciência econômica. Na segunda, apresenta-se a metodologia empregada na análise empírica e, por fim, na terceira, são discutidos os resultados decorrentes da aplicação dos modelos de regressão. Ao final do trabalho, o apêndice traz detalhes a respeito da metodologia empregada.

\section{ABORDAGEM TEÓRICA DA CRIMINALIDADE}

Quatro hipóteses podem ser arroladas na busca pela explicação da criminalidade sob a ótica da economia:

i. a criminalidade decorre de atos racionais deliberados por parte do infrator;

ii. a criminalidade apresenta um componente cíclico, aumentando nas fases de recessão e desaquecimento econômico e diminuindo nas fases de prosperidade.

Estas duas hipóteses parecem mais adequadas à explicação de crimes contra a propriedade.

iii. a criminalidade é um problema estrutural, decorrente da maior desigualdade social existente na economia contemporânea. Esta hipótese aplicar-se-ia tanto a crimes contra a propriedade quanto a crimes contra a pessoa;

iv. a criminalidade não guarda uma relação direta com variáveis socioeconômicas. A presente hipótese parece mais adequada à compreensão de crimes contra a pessoa.

\subsection{A Criminalidade é um Ato Racional}

A utilização da análise custo-benefício para o entendimento do processo de tomada de decisão dos indivíduos é uma tradição na teoria econômica. Desde fins do séc. XVIII e início do séc. XIX, nos escritos de Bentham, Say e Senior o agente econômico é considerado egoísta e racional, e visa à maximização da utilidade ou prazer derivados de seus atos e à minimização de seus custos ou sofrimento. (HUNT, 1985, cap. 6). Assim, desde que a utilidade ou benefício de uma ação supere seus custos, a ação será empreendida.

A análise custo-benefício pode, portanto, ser aplicada ao estudo de fenômenos bastante diversos, incluindo a questão da violência. Becker (1968) foi o primeiro autor a aplicar este instrumento ao estudo da criminalidade, tratando, em um primeiro momento, das 
penalidades ótimas e aplicando, em ensaios posteriores, a análise custo-benefício no nível individual. Para tanto, é necessário supor que o indivíduo que comete um crime e/ ou ato de violência o faz racionalmente, ou seja, de forma deliberada. ${ }^{3}$ Assim, o crime seria fruto de um cálculo prévio, onde os ganhos da atividade são comparados com seus custos. Se o benefício total (B) supera o custo total (C), tal que B > C, o indivíduo comete um ato ilícito.

Conseqüentemente, para se analisar a criminalidade do ponto de vista da racionalidade individual é necessário compreender os principais tipos de ganhos (benefícios) e de custos vinculados à atividade. Dentre esses, destacam-se Hellman e Alper (1993, cap. 3):

\section{Benefícios:}

Os benefícios da atividade criminal podem ser de dois tipos: monetários (Bmon), ou seja, a quantidade de dinheiro que se ganha (p. ex., num roubo) ou se deixa de gastar (p. ex., num caso de sonegação de impostos), com o ato ilícito aqui considerado como benefício monetário da atividade, ${ }^{4}$ e psicológicos (Bp), tais como a sensação de desafiar o sistema vigente, ludibriar as autoridades constituídas ou o simples prazer pessoal pela atividade ilícita, entre outras possibilidades.

Note que nesse enfoque o que importa é o cálculo individual do criminoso potencial. Para ele, o benefício total é a soma dos benefícios acima, tal que $\mathbf{B}=\mathbf{B}$ mon $+\mathbf{B p}$.

\section{Custos:}

Os custos da atividade criminal, por sua vez, podem ser divididos em quatro componentes:

\section{a) Custo material (Cmat)}

A execução de um ato ilícito envolve, muitas vezes, o uso de materiais e equipamentos, tais como armas, máscaras ou disfarces, documentos falsos etc., que implicam custos.

b) Custo de oportunidade (nw)

A execução e o planejamento de uma ação criminosa envolvem tempo, que poderia ser dedicado a outras atividades geradoras de renda ou lazer. Assim, há um custo de oportunidade vinculado ao ato ilícito, que corresponde à perda do rendimento potencial

3 Embora alguns tipos de crimes possam ser cometidos em momentos de irracionalidade ou forte emoção (in the heat of the moment), como em certos casos de estupro ou homicídio, onde não há um cálculo prévio dos custos e benefícios gerados pela ação.

4 O termo renda não é apropriado, desde que alguns atos implicam não a obtenção de um rendimento, mas economia de custos. 
proporcionado pelas atividades lícitas. Em geral, considera-se tal custo como equivalente à soma dos salários $(\mathrm{w})$ que seriam obtidos se o criminoso estivesse trabalhando nos $n$ períodos em que se dedicou ao ato ilícito.

c) Custo psicológico $(\mathrm{Cp})$ :

Da mesma forma que existem benefícios, há custos psicológicos associados à atividade criminal, como medo, ansiedade, sentimento de culpa, além do próprio desprazer provocado pela execução de um determinado ato (matar alguém, p. ex.).

d) Custo esperado de punição $(\theta F+\theta \gamma n w)$ :

Trata-se do custo esperado, já que a punição não é um evento certo. Há uma probabilidade de que o criminoso seja efetivamente punido $(\theta)$, isto é, capturado, julgado (se for o caso) e sentenciado. Conseqüientemente, a punição deve ser ponderada por esta probabilidade. $^{5}$

Pode-se pensar em dois tipos de punição: o pagamento de multas (F) e, desde que condenado - o que também não é um evento certo -, o indivíduo também pode ser preso. $\mathrm{O}$ custo da prisão depende, então, da probabilidade de condenação efetiva $(\gamma)$. Ou seja, o indivíduo, além de ser capturado, julgado e sentenciado $(\theta)$, deve ser efetivamente preso $(\gamma)$. Na prisão, o detento incorre no custo de oportunidade, que é representado pela perda dos salários que deixam de ser recebidos pelo fato de o indivíduo estar preso, durante o período da condenação ${ }^{6}$ (nw).

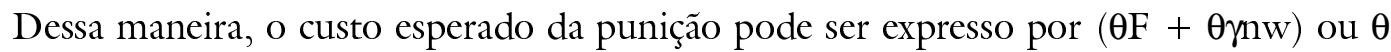
$(\mathrm{F}+\gamma \mathrm{nw})$. Logo, os custos totais são equivalentes $\mathrm{a}:^{7}$

$$
\mathrm{C}=\mathrm{Cmat}+\mathrm{nw}+\mathrm{Cp}+\theta(\mathrm{F}+\gamma \mathrm{nw})
$$

Conforme a análise anterior, o agente econômico racional optaria pela execução de um ato ilícito sempre que:

5 Que é risível no caso brasileiro: de cada cem crimes violentos (homicídios, latrocínios, estupros e roubos) um suspeito é detido em 24 casos, levado a julgamento em 14 casos e condenado à prisão em apenas cinco casos, ou seja, nosso $\gamma$ é de $5 \%$. Há ainda um agravante: somente em um caso a pena prisional é cumprida na íntegra. (Veja, 07/02/01, p. 87).

6 Isto é uma simplificação, já que: (i) a detenção implica custos psicológicos significativos, tais como a sensação de perda de liberdade, entre outros; (ii) não estamos levando em consideração o estigma que o preso passa a sofrer ao término de sua pena e que diminui sua expectativa futura de salário no mercado lícito de trabalho e; (iii) a possibilidade do indivíduo ser capturado, julgado e sentenciado $(\theta)$ varia de crime para crime.

7 O aumento dos custos de punição também poderia atuar no sentido de estimular a corrupção policial, na medida em que eleva o "preço" da liberdade do infrator detido. (SOARES, 2000, p. 34-35). Neste trabalho, tal efeito também será desconsiderado. 


$$
\mathrm{Bmon}+\mathrm{Bp}>\mathrm{Cmat}+\mathrm{nw}+\mathrm{Cp}+\theta(\mathrm{F}+\gamma \mathrm{nw})
$$

Dessa forma, a criminalidade poderia ser diminuída por meio de políticas públicas que restringem os benefícios ou elevam os custos da atividade ilícita. Esta tem sido a abordagem predominante no mainstream econômico.

\subsection{A Criminalidade Evolui de Acordo com o Ciclo Econômico}

Uma característica básica do sistema econômico é seu comportamento cíclico. Às fases de prosperidade e crescimento seguem-se fases de depressão e desaquecimento, em periodicidade maior ou menor.

É bastante presente a idéia de que a criminalidade mantém alguma relação com estes movimentos cíclicos, aumentando nas fases de depressão e diminuindo nas fases de crescimento econômico.

Desta forma, haveria uma relação direta entre criminalidade e desemprego, já que, dada a ausência de renda:

i. o custo de oportunidade de cometer um crime torna-se menor, conforme visto na seção anterior;

ii. maior a frustração das aspirações materiais do indivíduo, decorrente da incapacidade deste em satisfazer tais aspirações; e

iii. o mercado de trabalho "ilícito" passa a ser a alternativa de sobrevivência pessoal. Estes dois últimos itens serão explorados na próxima seção deste trabalho.

Esta relação, no entanto, deve ser analisada com cuidado porque, em primeiro lugar, o impacto do desemprego sobre os índices de criminalidade não é instantâneo. Supõe-se que o indivíduo que ingressa no contingente de desempregados, em condições normais, buscará sua reinserção no mercado de trabalho. Ainda que essa tentativa se mostre frustrada, o indivíduo tem o recurso a suas poupanças pessoais e ao segurodesemprego. Somente após esgotada parte destas economias é que o indivíduo cogitaria cometer um crime.

Isto traz dois desdobramentos:

- o desemprego cíclico propriamente dito, em geral, não induz à criminalidade, o que, de certa maneira, nega a própria hipótese; 
- na minoria de casos em que a criminalidade é induzida por este tipo de desemprego (os chamados criminosos episódicos ${ }^{8}$ ), este impacto não seria instantâneo, ou seja, há que se considerar a existência de uma defasagem temporal no processo de teste empírico da hipótese.

Além disso, o aumento do desemprego pode fazer com que os indivíduos permaneçam mais tempo em suas residências, reduzindo a vulnerabilidade dos alvos disponíveis para os criminosos. (SAPORI \& WANDERLEY, 2001, p. 46 a 49). Outro fator que deve ser levado em consideração é que o desemprego, ao rebaixar a renda média, tende a diminuir a recompensa pelo crime.

Assim, os resultados empíricos, possivelmente em razão do exposto, são controversos. Para ilustrar o fato, citam-se quatro informações de estudos referentes ao Brasil: ${ }^{9}$

- pesquisa realizada pelo Datafolha em 1991, com 645 presos da Casa de Detenção de São Paulo, constatou que no momento da infração somente $27 \%$ dos criminosos não estavam trabalhando. Ou seja, a maior parte dos infratores estava empregada. (Conjuntura Criminal, op. cit.).

- Andrade e Lisboa (2000), analisando a evolução da taxa de homicídios nos Estados de Minas Gerais, Rio de Janeiro e São Paulo, encontram uma certa inércia da criminalidade. E, o que é mais instigante, o desemprego parece atuar "contraciclicamente", isto é, haveria uma relação inversa entre este e as taxas de homicídio.

- Fernandes e Pereira (2001), por sua vez, estudando a evolução das taxas de furto e roubo de veículos na Grande São Paulo, encontram uma correlação positiva com a taxa de desemprego, entre outras variáveis explicativas.

- Também para Sapori e Wanderley (2001, p. 68), que estudaram a relação entre desemprego e criminalidade em quatro regióes metropolitanas brasileiras, "não foram encontrados indicios de que as variaçóes da taxa de desemprego implicariam variações presentes ou futuras dos indices de violência, inevitavelmente."

Dessa forma, a validade ou não da hipótese é controversa. De qualquer maneira, se há uma correlação ambígua entre criminalidade e desemprego, esta parece ser mais apropriada para explicar os crimes contra a propriedade.

8 O criminoso episódico é aquele que se alterna entre o mundo do crime e o mercado de trabalho - provavelmente informal - conforme a disponibilidade de empregos no mercado. (Conjuntura Criminal, maio/ 98).

9 Para um survey de outros estudos nacionais e internacionais relacionando desemprego e criminalidade, vide, entre outros, ARAUJO JR. \& FAJNZYLBER (op. cit.) e SAPORI \& WANDERLEY (op. cit.). 


\subsection{Crime e Contradição Social ${ }^{10}$}

Embora Marx e Engels não tenham discutido a questão de forma aprofundada, a teoria marxista tem muito a contribuir para a compreensão do fenômeno. Um elemento importante a ser considerado é o fato de que em uma formação social coexistem várias classes e sempre há antagonismos presentes, isto é, há, no mínimo, uma classe explorada e uma classe que se apropria de produto produzido por outros.

Na medida em que o desenvolvimento capitalista produz não apenas maior complexidade social, mas também exacerba as contradições sociais, o aumento dos índices de criminalidade poderia ser considerado, como uma conseqüência "lógica", decorrente de uma falha estrutural do sistema.

O aumento da criminalidade dar-se-ia, então, por quatro canais:

- O acirramento das contradiçôes sociais ocorre à medida que o sistema capitalista gera desemprego (devido ao progresso tecnológico) e empregos de má qualidade que não preenchem as necessidades financeiras de seus ocupantes - contribuindo para uma maior desigualdade social. Dessa forma, é comum encontrarmos autores de diversas correntes de pensamento utilizando o Índice de Gini como variável explicativa para o fenômeno (p. ex., MENDONCA, 2002).

No entanto, há que se ter cuidado com tal análise, já que no Brasil, entre 1995 e 1998, constata-se uma relação inversa entre o Índice de Gini e a taxa de homicídios. Nos dois anos seguintes, porém, essa tendência se inverte, conforme ilustrado pela tabela a seguir.

Ou seja, é necessário complementar tal análise com outros indicadores de contradição social (por exemplo, evolução do contingente de indivíduos sem rendimentos).

\section{TABELA 1 - ÍNDICE DE GINI E TAXA DE HOMICÍDIOS - BRASIL - 1995/2000}

\begin{tabular}{lcc}
\hline Ano & Índice de Gini & Taxa de Homicídios (por cem mil hab.) \\
\hline 1995 & 0,585 & 23,85 \\
1996 & 0,580 & 24,05 \\
1997 & 0,580 & 24,91 \\
1998 & 0,575 & 25,84 \\
1999 & 0,567 & 23,23 \\
2000 & 0,609 & 23,52 \\
\hline
\end{tabular}

Fonte: IBGE, Conjuntura Criminal.

10 Esta seção está baseada principalmente em GREENBERG (1993), que organizou uma compilação de obras de autores de inspiração marxista, buscando nesta corrente de pensamento explicações para a questão da violência. 
- Complementando a idéia anterior, o crime pode ser visto como mecanismo de mobilidade social para grupos excluídos ou discriminados dentro de uma comunidade. Na medida em que estes grupos não têm acesso a postos regulares e bem remunerados no mercado de trabalho, a atividade criminal passa a ser a alternativa viável de ascensão social. Esta é uma explicação plausível para o envolvimento de jovens em atividades ilícitas, principalmente as ligadas ao tráfico de drogas e outras formas de crime organizado. ${ }^{11}$

- Um terceiro canal pelo qual se daria o incremento da criminalidade no capitalismo diz respeito ao aumento dos crimes corporativos, popularmente conhecidos como "crimes de colarinho branco", que ocorreria em razão da maior concentração do capital que, ao elevar a autonomia e o poder político das grandes corporações, possibilita que estas empreendam estratégias para burlar a legislação (BARNETT, 1993), bem como de rent-seeking e também da tendência à queda da taxa de lucro, que seria uma conseqüência da menor exploração do trabalho vivo em decorrência do uso intensivo de tecnologia. Tendo em vista que essa é uma característica estrutural do capitalismo, os crimes corporativos configurariam uma estratégia corporativa de busca de fontes "alternativas" de faturamento a ser potencialmente cada vez mais utilizada.

- A intensificação das conseqüências negativas do capitalismo, expressas nos canais anteriormente citados, poderia desencadear ações criminosas no sentido de romper ou transformar a estrutura vigente. Embora Marx e Engels condenassem as manifestaçôes individuais criminosas como "destrutivas para o progresso da revolução" (WENGER \& BONOMO, 1993, p. 675 a 678), esta pode ser uma explicação bastante razoável para alguns atos terroristas, por exemplo. ${ }^{12}$

Os três últimos canais, quando considerados do ponto de vista individual, podem perfeitamente ser enquadrados no esquema da análise custo-benefício, discutido na seção 1.1 deste estudo. É necessário frisar, porém, que do ponto de vista da compreensão da criminalidade é mais correto considerar-se à parte tais canais, na medida em que estes podem ser vistos mais como uma decorrência de falhas estruturais do sistema econômico capitalista do que como uma opção deliberada dos indivíduos nele inseridos.

11 Esta hipótese poderia ser complementada por uma explicação de fundo psicológico: o atendimento a necessidades básicas do ser humano, tais como a de sobrevivência (material) e a de pertencer a um grupo social. A esse respeito, vide MASLOW (1970).

12 Neste, como em casos de crimes de guerra ou de motivação religiosa, o ato pode ser visto até como meritório, devido à falta de empatia para com as potenciais vítimas. 


\subsection{Crime: Um Ato Impensado}

A última hipótese, de que a criminalidade não guarda uma relação direta com variáveis socioeconômicas, atribui o fenômeno a fatores de cunho psicológico, cultural-antropológico ou de interação social. Assim, a violência seria decorrente de: ${ }^{13}$

i. patologias individuais de natureza biológica (cuja origem foram as teorias de Lombroso, no final do séc. XIX), psiquiátrica ou psicológica. A teoria do autocontrole, p. ex., atribui o comportamento desviante a uma deformação no processo de socialização da criança, qual seja, a ausência de autocontrole;

ii. especificidades culturais/religiosas/antropológicas de determinadas regiões ou etnias, como, p. ex., a predisposição para resolver conflitos interpessoais de forma violenta, presença de conflito de terras ou de atividades ilegais lucrativas (tráfico de drogas, jogo) (ARAUJO JR. \& FAJNZYLBER, op. cit., p. 372) ou ampla disponibilidade de $\operatorname{armas}^{14} \mathrm{e}$

iii. "má-interação social", ou seja, má influência exercida sobre o indivíduo pela convivência com infratores, às vezes até no próprio seio familiar. Alguns autores tentaram mensurar os efeitos da interação social, como Sah (1991), Glaeser, Sacerdote e Scheinkman (1996) e Mendonça, Loureiro e Sachsida (2003).

Esta hipótese aplicar-se-ia mais aos crimes contra a pessoa do que aos crimes contra a propriedade.

\section{A CONSTRUÇÃO DE UM MODELO PARA ANÁLISE EMPÍRICA}

A investigação das variáveis socioeconômicas de um município, por bairros, tem nos Censos Demográficos do IBGE uma fonte de informações privilegiada. Esta fonte, porém, apresenta dois problemas:

i. defasagem temporal, visto que os Censos são realizados decenalmente;

ii. abrangência restrita, isto é, apesar da disponibilidade de uma ampla gama de informações, o Censo não compreende variáveis importantes, como a taxa de desemprego, apenas para citar um exemplo.

13 Para um bom e recente levantamento sobre as diversas teorias que contribuiriam para a compreensão da criminalidade, vide CERQUEIRA \& LOBÃO (2003a).

14 A esse respeito, há um interessante documentário intitulado Tiros em Columbine, do diretor norte-americano Michael Moore, que vale a pena ser assistido. 
Desta forma, em setembro de 2002 foi realizada uma pesquisa de campo destinada a preencher as lacunas do Censo Demográfico, bem como para captar algumas variáveis qualitativas de percepção da violência por parte da população aracajuana, abrangendo os 35 bairros censitários do município, e também Santa Maria, que embora não seja considerado um bairro isolado pelo IBGE, no presente trabalho mereceu este tratamento por sua importância em um estudo acerca das causas da violência.

Nessa pesquisa foram entrevistados 3.240 indivíduos. É importante frisar que, para um intervalo de confiança de $95 \%$ com margem de erro de $4 \%$, seria suficiente uma amostra de cerca de 1.400 indivíduos para o conjunto do município. Trabalhou-se com uma amostra mais ampla com vistas a ampliar a representatividade das respostas também em nível dos bairros (foram entrevistadas 90 pessoas por bairro).

De posse dos dados da pesquisa e do Censo Demográfico, procedeu-se à elaboração de um modelo econométrico básico a ser posteriormente desdobrado em dois subconjuntos de regressões múltiplas: um conjunto para a análise dos crimes contra o patrimônio e outro para estudo dos crimes contra a pessoa. O modelo básico é o seguinte:

Taxa de criminalidade $=\mathrm{f}\left(\mathrm{U}, \mathrm{Y}, \mathrm{I}_{\mathrm{G}}, \mathrm{Tm}\right.$, Infra, Conf, Escol, $\mathrm{EF}$, Feta , Dens $)$

$$
(+/-)(+/-)(+) \quad(-) \quad(-) \quad(-) \quad(-) \quad(-) \quad(-) \quad(+)
$$

Onde:

$\mathrm{U}=$ desocupação

$\mathrm{Y}=$ renda

$\mathrm{I}_{\mathrm{G}}=$ concentração da renda

$\mathrm{Tm}=$ vínculo com o bairro

Infra $=$ infra-estrutura do bairro

Conf $=$ confiança nas instituiçôes

Escol $=$ nível de escolaridade

$\mathrm{EF}=$ estrutura familiar

Feta $=$ estrutura etária

Dens $=$ densidade demográfica

Os sinais entre parênteses indicam o efeito esperado de cada variável sobre a taxa de criminalidade. Assim, a confiança nas instituiçốes, por exemplo, atua no sentido de restringir os atos ilícitos.

Passemos, então, à descrição detalhada das proxies utilizadas para representar as variáveis do modelo básico. 
No caso da variável dependente, foram calculadas duas taxas de criminalidade: uma referente aos crimes contra o patrimônio e outra relativa aos crimes contra a pessoa.

a) Taxa de Crime contra o patrimônio (patrimon)

Os crimes contra o patrimônio abrangem: total de roubos, total de furtos, dano, estelionato, apropriação indébita e latrocínio.

b) Taxa de Homicídios (homicid):

Como proxy para o crime contra a pessoa foram escolhidos os casos mais extremos que implicam perda e/ou risco de vida para a vítima, quais sejam, os homicídios culposos, dolosos e tentados. ${ }^{15}$

Em ambos os casos as informações foram cedidas pela Polícia Civil do Estado de Sergipe e compreendem o primeiro semestre de 2002. Os dados referentes às 106 áreas de cobertura das Delegacias Metropolitanas, restritas ao município de Aracaju, foram reorganizados e compatibilizados com os 35 bairros censitários e mais o bairro Santa Maria, para o qual a Prefeitura Municipal de Aracaju dispóe de dados do IBGE desagregados. ${ }^{16}$

O número absoluto de crimes foi então dividido pela população de cada bairro e multiplicado por 10.000, de forma que as taxas estão expressas em $\mathrm{n}^{\circ}$ de ocorrências por dez mil habitantes.

Com relação às variáveis explicativas, foram utilizados os seguintes dados:

\section{Desocupação:}

A taxa de desemprego, calculada para cada um dos bairros a partir dos dados obtidos pela pesquisa de campo coordenada pelos autores, foi utilizada como proxy para a desocupação. Foi caracterizado como desempregado o indivíduo que não estava trabalhando no momento da entrevista e que havia procurado uma ocupação nos trinta dias anteriores. ${ }^{17}$ Dessa forma:

15 Essa informação, no entanto, apresenta problemas porque, devido ao sub-registro, há um número muito baixo de ocorrências, o que dificulta a análise estatística. O sub-registro ocorre porque os dados provêm da Polícia Civil, cuja principal fonte estatística são os boletins de ocorrência (B.Os). Segundo a equipe do CODEPE, dificilmente se lavra um B.O. em casos de homicídio. Por conta disso, a partir de 2003 iniciouse um processo de compatibilização entre os dados do IML e os da Polícia Civil no Estado de Sergipe. Tais dados, porém, não estão disponíveis para o período analisado neste trabalho.

16 Já que, nas tabelas do Censo, Santa Maria está incluído nos dados "sem especificação".

$17 \mathrm{O}$ indivíduo que não estava trabalhando e não procurou emprego foi classificado como inativo. 
Taxa de desemprego $=\mathrm{n}^{\mathrm{o}}$ de desempregados

(desemp) PEA

onde a PEA - População Economicamente Ativa - equivale à soma de ocupados e desempregados. Como anteriormente mencionado, a correlação entre o desemprego e as taxas de criminalidade é ambígua, podendo ser positiva ou negativa.

\section{Renda:}

A pesquisa de campo também gerou os dados com relação à renda familiar do entrevistado. Embora o Censo Demográfico 2000 apresente os dados de rendimento por bairro, a informação limita-se à renda do indivíduo responsável pelo domicílio. Dessa forma, nossos dados são mais abrangentes, pois englobam a renda familiar. Além disso, nos dois anos que separam as coletas de dados do Censo e da nossa pesquisa pode ter havido um "envelhecimento" das informaçôes do primeiro, no sentido de que alteraçôes da conjuntura econômica e no mercado de trabalho podem ter provocado mudanças naqueles dados.

As informações obtidas foram então estratificadas em oito faixas de renda, e com isso puderam ser geradas duas variáveis adicionais:

- insuficiência de renda: porcentual de entrevistados no bairro pertencentes aos dois extratos inferiores, ou seja, cuja renda familiar era de até R \$ 400,00 (dois salários mínimos à época da pesquisa). Tal variável pode ser considerada como uma medida de pobreza;

- concentração de renda: aqui representada pelo Índice de Gini, medida de distribuição da renda que varia entre 0 e 1. Quanto maior o Índice de Gini (mais próximo da unidade), maior a concentração da renda. (JORGE, 2000, p. 84). Para o cálculo do Índice de Gini quando se dispóe apenas de informaçôes por extratos de renda é necessário arbitrar a renda média de cada extrato. Para mais informações sobre o cálculo do Índice, vide Hoffmann (1998).

A renda exerce um efeito ambíguo sobre a criminalidade, de forma que o sinal esperado pode ser positivo ou negativo. Já a pobreza tende a exercer um efeito positivo, na medida em que o crime poderia ser uma alternativa para superar as privações. A concentração da renda, por sua vez, estimula a prática de ilícitos patrimoniais tendo em vista que a maior desigualdade 
"reforçaria a disposição a cometer crimes nas pessoas pobres de duas formas: a baixa renda própria e a alta renda alheia... (e) a teoria da frustraçãoagressão. A frustração das necessidades e das expectativas levaria os sujeitos a desabafar através da agressão." (CANO \& SANTOS, 2000, p. 1).

\section{Vínculo com o bairro:}

O vínculo com o bairro foi aferido pelo tempo de moradia do entrevistado. A idéia básica é a de que quanto maior o tempo de residência no local, maior o vínculo com a comunidade, o que colabora para restringir a criminalidade e vice-versa. Segundo Cardia e Schiffer (2002, p. 25):

\section{"A estabilidade da população em seu bairro é apontada como um fator que está associado a uma maior coesão social e disposição dos moradores para agirem em prol do bem comum e até para intervir de forma a evitar atos de violência e/ou situações de risco que afetem grupos vulneráveis."}

Nesse sentido, trabalhamos com o porcentual de moradores com até dois anos de moradia no bairro, ou seja, com um tênue vínculo com a comunidade. Assim, quanto maior esse porcentual, maior tenderia a ser a criminalidade, isto é, espera-se que haja uma correlação positiva entre ambos.

\section{Infra-estrutura:}

A infra-estrutura dos bairros foi analisada pela existência de quatro bens públicos: ${ }^{18}$ espaço para prática de esportes ou lazer, escola, posto de saúde e posto policial. Há duas possibilidades para se mensurar tal disponibilidade:

i. utilização de variáveis dummy - 0 para a ausência ou 1 para indicar a presença de cada um dos referidos bens públicos; ou

ii. utilização dos porcentuais de respostas afirmativas, reportando a existência do bem público no bairro.

A segunda estratégia foi escolhida por refletir melhor a percepção dos moradores com relação à infra-estrutura de seu bairro, pois é justamente esta percepção, mais do que a existência objetiva em si, que pode induzir o indivíduo a um ato ilícito ou violento.

Também a existência de um posto de policiamento comunitário foi avaliada. Neste caso, por se tratar de um fato objetivo, trabalhou-se com uma variável dummy - 0 para a

18 O termo bem público não é o mais adequado porquanto não foi explicitado, para os entrevistados, se se tratava de escola ou posto de saúde públicos ou privados. No primeiro caso, dada a garantia de acesso gratuito, tais itens configuram-se realmente como bens públicos, pois além do princípio da náo-rivalidade, atendem ao princípio da não exclusão, o que já não é verdadeiro no segundo caso. 
ausência ou 1 para indicar a presença do posto. ${ }^{19}$ Nosso intuito foi verificar se esta modalidade de policiamento, com maior vínculo com a comunidade, tem produzido resultados palpáveis.

A sensação de que o bairro possui uma infra-estrutura adequada tende a restringir a criminalidade, de modo que se espera por um sinal negativo para o conjunto de variáveis indicativas da infra-estrutura. ${ }^{20}$

\section{Confiança nas instituições:}

A confiança nas instituições, por sua vez, foi mensurada da seguinte forma: os entrevistados expressaram seu nível de confiança na Polícia e na Justiça, atribuindo a estas instituições uma nota de zero a dez. Para cada bairro foram, então, calculados os porcentuais de notas inferiores a cinco, ou seja, o nível de reprovação com relação à Polícia e à Justiça. Quanto maior a reprovação, menor é a confiança nas instituiçốes e menor será o custo moral de se infringir a lei, bem como deve haver maior sensação de impunidade. Em ambos os casos, como estamos medindo, na verdade, a falta de confiança nas instituiçôes, espera-se por um sinal positivo entre estas variáveis e a criminalidade.

\section{Escolaridade:}

Outra variável analisada foi o grau de escolaridade. Neste caso, a informação provém do Censo Demográfico 2000 e se refere aos anos de estudo dos indivíduos responsáveis pelos domicílios particulares permanentes. Dessa forma, calculou-se o porcentual de responsáveis pelos domicílios com até três anos de estudo. O baixo nível educacional, tanto de vítimas como de infratores, acarreta três conseqüências:

i. diminuição da renda, decorrente da menor produtividade do trabalho. Isto tem um efeito ambíguo sobre a criminalidade, pois ao mesmo tempo em que diminui o "prêmio" pelo crime, diminui também o custo do ato ilícito;

ii. menor respeito às instituiçốes e ao contrato social, o que poderia exacerbar a criminalidade; ${ }^{21} \mathrm{e}$

19 Os dados foram fornecidos pela Polícia Militar do Estado de Sergipe, e se referem ao bairro de localização do PAC. Não foi levado em consideração o número de policiais existentes em cada posto, bem como o fato de que um PAC pode atender ou dar suporte ao policiamento em mais de um bairro.

20 A ocorrência de um sinal positivo no caso dos crimes contra o patrimônio não deve, porém, ser descartada na medida em que os bairros com melhor infra-estrutura são, em geral, aqueles que concentram os moradores de renda mais elevada, onde o "prêmio" pelo crime é maior.

21 Aparentemente, o grau de escolaridade realmente influencia o julgamento das instituiçôes, pois existe uma correlação positiva entre baixa escolaridade e o grau de desconfiança na Polícia e na Justiça: o $r$ de Pearson foi de, respectivamente, 0,52 e 0,384 . 
iii. menor consciência dos riscos da violência que, aliada ao menor poder aquisitivo, limita a aquisição de equipamentos de proteção por parte das vítimas, tornando-as mais vulneráveis e colaborando para o aumento da criminalidade.

Assim, a despeito de uma possível ambigüidade, ${ }^{22}$ espera-se um sinal positivo para a correlação entre a baixa escolaridade e a taxa de criminalidade.

\section{Estrutura familiar:}

A estrutura familiar também foi analisada com o intuito de se aferir o porcentual de famílias uniparentais existente nos bairros. No caso da ausência de um dos cônjuges, presume-se ser maior a dificuldade para educar e controlar o comportamento dos filhos. Neste sentido, a maior presença de famílias uniparentais poderia estar correlacionada com o aumento da criminalidade. ${ }^{23}$ Esta informação provém da pesquisa de campo.

\section{Estrutura etária:}

Uma variável de extrema importância no estudo da criminalidade é a estrutura etária da população, notadamente no que diz respeito à participação porcentual dos jovens, ${ }^{24}$ já que:

\section{"em todo o mundo os crimes violentos tendem a ser praticados por jovens do sexo masculino entre os quinze e os trinta anos, mais especificamente entre os dezessete e os 25 anos.” (SOARES, 2000, p. 350).}

A participação porcentual dos jovens nos bairros foi aferida para as faixas de 15 a 19 anos (FETA1) e de 15 a 24 anos (FETA2), com dados provenientes do Censo. As duas faixas não podem ser utilizadas simultaneamente no modelo devido à sua elevada colinearidade. O sinal esperado é positivo, na medida em que a maior participação dos jovens no total da população tende a elevar a criminalidade.

\section{Densidade demográfica:}

Por fim, incluiu-se também a densidade demográfica, tal que:

$$
\text { DENS }=\frac{\mathrm{n}^{\mathrm{o}} \text { de habitantes no bairro }}{\text { extensão do bairro }\left(\mathrm{km}^{2}\right)}
$$

22 Por outro lado, um maior nível de escolaridade poderia criar oportunidades de crime mais rentáveis ao potencial infrator: MENDONÇA, LOUREIRO \& SACHSIDA (2003, p. 4) mostram que enquanto 16,6\% dos encarcerados no presídio da Papuda por tráfico de drogas tinham nível superior completo, nenhum preso daquele estabelecimento detido por estupro ou homicídio possuía tal nível de escolaridade.

23 ARAUJO JR \& FAJNZYLBER (2001, p. 346/7) citam evidências dessa correlação positiva.

24 Dentre alguns estudos que atribuem importância à variável podem ser citados os de ARAUJO JR. \& FAJNZYLBER (2001), ANDRADE \& LISBOA (2000) e MELLO JORGE (2002). 
A população provém do Censo Demográfico, ao passo que a informação da extensão territorial dos bairros foi fornecida pela Prefeitura Municipal de Aracaju. O intuito de se trabalhar com a densidade demográfica é verificar se a maior concentração populacional, ao aumentar o anonimato e dificultar o controle do comportamento individual, poderia estimular o incremento da criminalidade, de forma que se espera por uma correlação positiva entre ambas as variáveis. (CANO \& SANTOS, 2000; ARAUJO JR. \& FAJNZYLBER, 2001, entre outros).

Como se pode perceber, os dados utilizados neste trabalho provêm de duas fontes principais: o Censo Demográfico 2000 elaborado pelo IBGE e a pesquisa de campo realizada no âmbito desta pesquisa em set/2002.

A observação dos dados permite a identificação de um outlier: a taxa de crimes contra o patrimônio do Centro - 2.090,6 ocorrências por dez mil - destoa amplamente das demais. Nesse caso, o outlier foi tratado com a inclusão de uma variável dummy (DPATR) utilizada apenas no modelo de crimes contra o patrimônio - na qual atribuise valor 1 para o Centro e zero para os demais bairros do município.

Apresenta-se, em seguida, a base de dados construída de acordo com os procedimentos mencionados acima.

O modelo básico foi desdobrado em dois: um para explicar os crimes contra o patrimônio e outro para explicar os homicídios. Cada uma das variáveis dependentes foi regredida contra o mesmo conjunto de variáveis explicativas - à exceção da dummy para o Centro, utilizada apenas no primeiro modelo.

Como o número de variáveis independentes é muito elevado, representando riscos significativos de violação dos pressupostos básicos do modelo de regressão, optou-se pela realização de uma regressão do tipo stepwise para "filtrar" as variáveis explicativas. Para se testar a qualidade da seleção feita por meio deste processo efetuou-se também uma Análise de Componentes Principais com o conjunto de variáveis independentes. Os agrupamentos resultantes dessa análise foram coerentes com os resultados do processo stepwise, reafirmando sua consistência. Os resultados da estimação são apresentados na seção subseqüiente. 


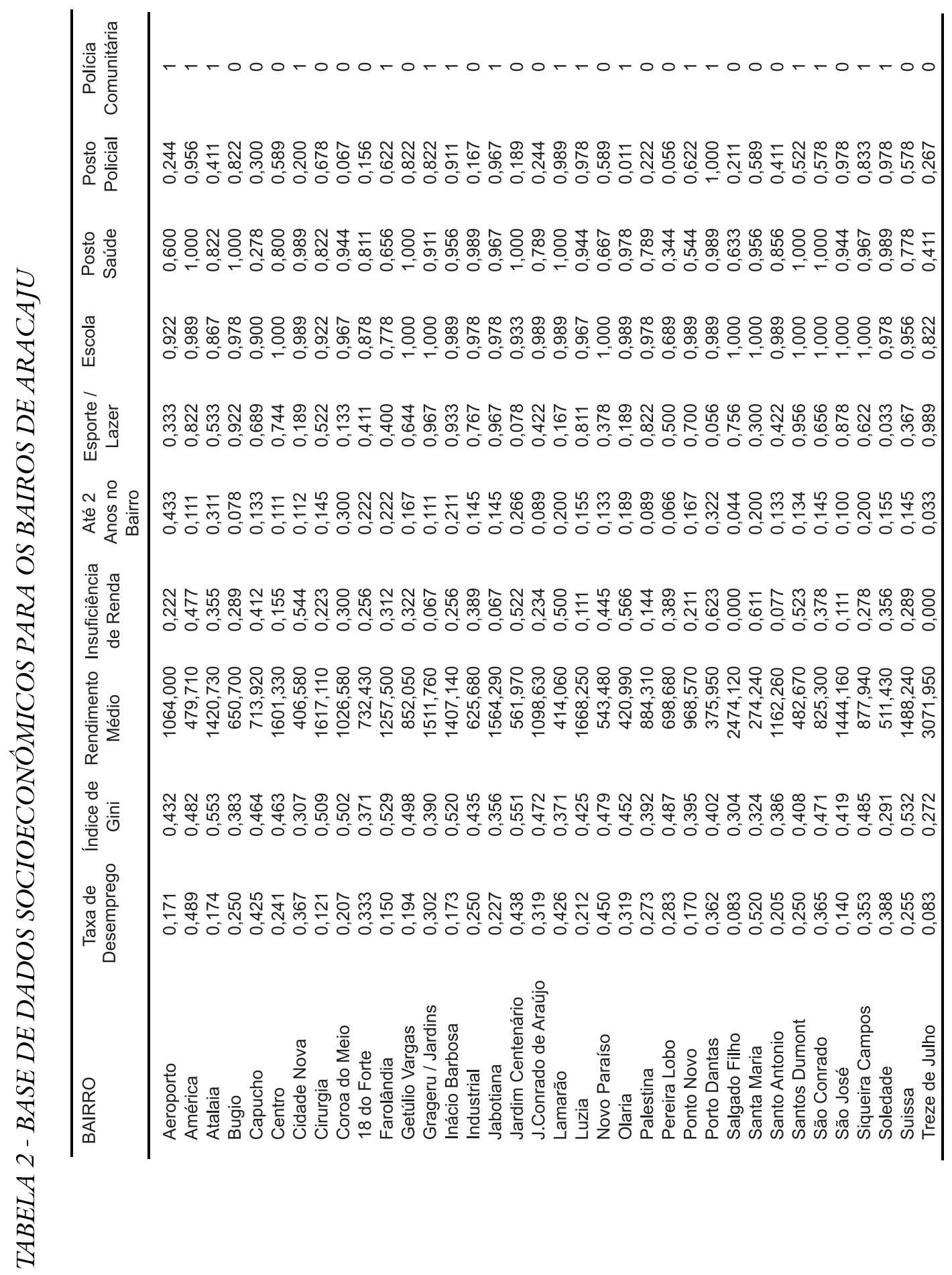

Est. econ., São Paulo, 35(3):569-594, jul-set 2005 


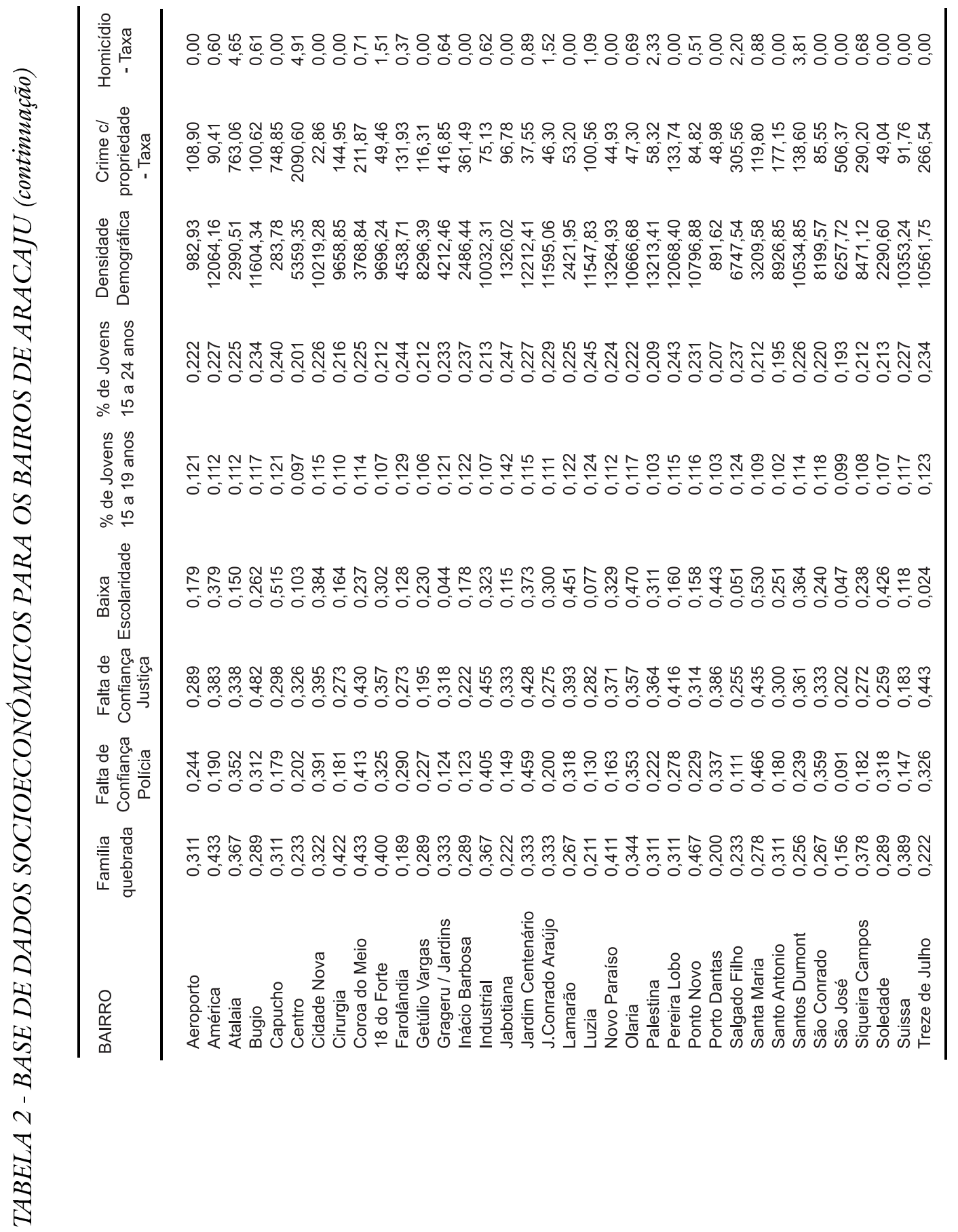




\section{RESULTADOS}

\subsection{Modelo para o Crime contra o Patrimônio}

Nas Tabelas 3 e 4 apresentam-se os resultados obtidos para as variáveis significativas, bem como para as variáveis excluídas via procedimentos descritos na seção anterior, para um nível de significância de $5 \%$.

\section{TABELA 3 - ESTATÍSTICAS E COEFICIENTES DA REGRESSÃO}

\begin{tabular}{|c|c|c|c|c|c|}
\hline \multirow{4}{*}{$\begin{array}{l}\mathrm{R} 2=0,905 \\
\text { Modelo }\end{array}$} & \multicolumn{2}{|c|}{$F=46,276$} & $s=124,163$ & \multicolumn{2}{|c|}{ d.w. $=1,957$} \\
\hline & \multicolumn{2}{|c|}{ Coeficientes Não } & Coeficiente & \multirow[b]{3}{*}{$t$} & \multirow[b]{3}{*}{ Sig. } \\
\hline & \multicolumn{2}{|c|}{ Padronizados } & Padronizado & & \\
\hline & B & Desvio Padrão & B & & \\
\hline CONST. & 950,779 & 373,607 & & 2,545 & 0,017 \\
\hline DPATR & 1632,266 & 140,734 & 0,740 & 11,598 & 0,000 \\
\hline DENS & $-0,0287$ & 0,006 & $-0,320$ & $-5,162$ & 0,000 \\
\hline ESPORTE & 326,978 & 76,728 & 0,264 & 4,262 & 0,000 \\
\hline GINI & 707,428 & 281,862 & 0,146 & 2,510 & 0,018 \\
\hline SAUDE & $-310,877$ & 108,522 & $-0,169$ & $-2,865$ & 0,008 \\
\hline FETA1 & $-6815,88$ & 2763,678 & $-0,167$ & $-2,466$ & 0,020 \\
\hline
\end{tabular}

TABELA 4 - ESTATÍSTICAS DAS VARIÁVEIS EXCLUÍDAS

\begin{tabular}{lccccc}
\hline Variável & $\begin{array}{c}\text { Coeficiente B } \\
\text { Padronizado }\end{array}$ & $\mathrm{t}$ & Sig. & VIF & $\begin{array}{c}\text { Tolerância } \\
\text { Mínima }\end{array}$ \\
\hline DESEMP & 0,009 & 0,129 & 0,898 & 1,298 & 0,715 \\
RENDA & 0,099 & 1,362 & 0,184 & 1,672 & 0,598 \\
POBREZA & $-0,008$ & $-0,105$ & 0,917 & 1,690 & 0,592 \\
TEMPO & $-0,114$ & $-1,258$ & 0,219 & 2,569 & 0,389 \\
ESCOLA & 0,002 & 0,025 & 0,981 & 2,011 & 0,497 \\
POLICIA & $-0,093$ & $-1,288$ & 0,208 & 1,619 & 0,618 \\
PAC & $-0,013$ & $-0,181$ & 0,857 & 1,554 & 0,604 \\
FAMILIA & 0,014 & 0,209 & 0,836 & 1,423 & 0,703 \\
DESPOL & 0,026 & 0,359 & 0,723 & 1,544 & 0,595 \\
DESJUS & 0,014 & 0,216 & 0,830 & 1,198 & 0,701 \\
BESCOL & $-0,017$ & $-0,232$ & 0,819 & 1,606 & 0,623 \\
\hline
\end{tabular}


Conforme ilustrado no apêndice, todos os pressupostos do modelo de regressão linear múltipla são respeitados, o que indica que os coeficientes estimados são eficientes e os sinais estão corretos. Passemos à discussão das implicações práticas desse resultado.

O coeficiente de determinação do modelo é de $90,5 \%$, tendo papel de destaque na explicação do fenômeno as seguintes variáveis:

\section{i. Estrutura Etária (Fetal)}

A participação dos jovens no total da população aparece como variável significativa, mas com sinal negativo - ao contrário do esperado -, denotando que os crimes contra o patrimônio ocorrem predominantemente em bairros de estrutura etária mais "velha". É importante frisar que os resultados do modelo pouco se alteram quando se utiliza a faixa etária de 15 a 24 anos (Feta2) e o sinal negativo para a variável se mantém.

O esclarecimento dessa aparente contradição pode estar na mobilidade espacial. Nada impede que os jovens de um bairro cometam crimes em outros, pois:

"as taxas agregadas... são usadas na suposição de que vitimas e criminosos babitam a mesma área. Quanto menor a área geográfica usada na comparação mais difícil é sustentar essa suposição.” (CANO \& SANTOS, 2000).

Assim, em um estudo como este - por bairros - a mobilidade espacial poderia dificultar a percepção de determinados fatos, bem como falsear hipóteses. De qualquer maneira, fica aqui um tema para investigação futura.

\section{ii. Infra-estrutura do Bairro}

Os crimes contra o patrimônio parecem ocorrer predominantemente em bairros sem posto de saúde, mas com local para a prática de esportes ou lazer. Este fato peculiar pode ser esclarecido por meio da matriz de correlação das variáveis independentes: os bairros habitados pela população de maior renda são justamente os que costumam apresentar estas características de ausência de posto de saúde, porém com existência de espaço para a prática de esportes ou lazer. O $\mathrm{r}$ de Pearson indicando a correlação entre a renda e os bens públicos aqui citados é de, respectivamente, $-0,372$ e 0,492.

iii. Densidade Demográfica

Os bairros de menor densidade parecem concentrar os ilícitos patrimoniais, exibindo sinal contrário ao esperado para a variável. Porém essa aparente contradição pode ser explicada se considerarmos que muitos bairros de Aracaju são densos, não tanto em ra- 
zão de um contingente populacional expressivo, mas por causa de sua reduzida extensão geográfica. Neste caso, a densidade demográfica pode não limitar o controle social, conforme o previsto.

Nesse sentido, os crimes contra o patrimônio não necessariamente ocorrem nos bairros mais densos, da mesma forma que a maior densidade demográfica não se configura, em Aracaju, como garantia de anonimato e liberdade de comportamento social.

iv. Concentração de renda

A desigualdade social influencia a criminalidade contra o patrimônio da maneira prevista, isto é, o contraste entre a abundância e a escassez incentiva a prática do ilícito patrimonial.

Por fim, a dummy de nível destinada a corrigir a presença do outlier também interferiu no resultado da estimação.

\subsection{Modelo para o Crime contra a Pessoa}

Procedimento idêntico foi utilizado para analisar o comportamento da taxa de homicídios em Aracaju. Todas as regressões, porém, apresentaram resultados muito ruins. Há duas razões possíveis para o ocorrido:

i. as variáveis adequadas à explicação dos crimes contra o patrimônio não o são para explicar os homicídios, o que nos deixaria próximos da quarta hipótese discutida na seção 1.4. Esta foi a conclusão a que chegaram Mendonça, Loureiro e Sachsida (2002) após entrevistarem 799 internos do presídio da Papuda em Brasília:

"pôde-se constatar que a motivação por trás do agente responsável por cometer um crime não violento parece estar, de fato, mais relacionada a fatores econômicos, enquanto que por trás da prática de um crime violento a motivação parece estar mais relacionada a fatores de interação social." (p. 623).

Embora esta seja uma possibilidade real, nosso modelo contém variáveis para captar a "interação social", além de variáveis utilizadas com sucesso para explicar o comportamento dos homicídios em diversos estudos. Dessa forma, o problema parece estar não nas variáveis explicativas, mas na variável dependente.

ii. a variável dependente apresenta problemas. Este parece ser o principal empecilho neste trabalho, já que os dados foram cedidos pela Polícia Civil, cuja base são os 
boletins de ocorrência (B.O.s). Em casos de homicídio, porém, raramente se lavra um B.O., ou seja, a informação de homicídios padece de sub-registro. A alternativa - utilizar as estatísticas do Instituto Médico Legal (IML) - melhora, mas não resolve o problema, pois, freqüentemente, não é indicado o bairro do óbito, apenas o município.

O sub-registro, em uma cidade de médio porte como Aracaju e para um período de tempo restrito de análise (um semestre, em nosso caso), pode se configurar como um empecilho fatal, pois reduz o número de casos. Assim, 17 dos 36 bairros não contabilizaram qualquer homicídio no $1^{\circ}$ semestre de 2002 e 12 bairros apresentaram um único caso no mesmo período. Com isso, o vetor de dados da variável dependente tornase bastante singular, com a presença de muitos zeros, o que acaba por inviabilizar a análise. De qualquer modo, aqui reside outro tópico bastante interessante para investigação posterior.

\section{CONSIDERAÇÕES FINAIS}

Este trabalho teve o objetivo de investigar as razões socioeconômicas da criminalidade em Aracaju. Para tanto, foram coletadas informações do Censo Demográfico 2000 e de uma pesquisa de campo coordenada pelos autores compreendendo uma amostra de 3.240 indivíduos. Esta base de dados serviu para a elaboração de um modelo básico de criminalidade. Tal modelo foi desdobrado para explicar os crimes contra o patrimônio e os homicídios no município.

O segundo modelo não pôde ser aplicado com êxito devido a problemas apresentados pela variável dependente. $\mathrm{O}$ modelo destinado à análise dos crimes contra o patrimônio, no entanto, explicou cerca de $90 \%$ do fenômeno. As variáveis responsáveis por tal comportamento foram: a concentração de renda, características da infra-estrutura existente nos bairros, a baixa densidade demográfica e a menor participação dos jovens no total da população.

Este resultado incomum parece indicar que as razões socioeconômicas da criminalidade contra o patrimônio em uma cidade de porte médio não são as mesmas ou, principalmente, que não atuam da mesma forma como operam nos grandes centros urbanos como Rio de Janeiro ou São Paulo. A mobilidade espacial também pode ter contribuído para obscurecer algumas relaçôes. De qualquer maneira, um aprofundamento do estudo ora realizado seria de grande valia. 


\section{REFERÊNCIAS BIBLIOGRÁFICAS}

ANDRADE, M.; LISBOA, M. Hopeless life: homicide in Minas Gerais, Rio de Janeiro and São Paulo: 1981 to 1997. Belo Horizonte, 2000. Mimeografado.

ARAÚJO JR, A.; FAJNZYLBER, P. Violência e criminalidade. In: LISBOA, M.; MENEZES FILHO, N. (orgs.), Microeconomia e sociedade no Brasil. Rio de Janeiro: Contracapa/FGV, 2001.

BARNETT, $H$. Wealth, crime and capital accumulation. In: GREENBERG, David (ed.), Crime and capitalism: readings in Marxist criminology. Filadelfia: Temple University, 1993.

BEATO FILHO, C. Determinantes da criminalidade em Minas Gerais. Revista Brasileira de Ciências Sociais, v. 13, n. 37, jun. 1998.

BECKER, G. Crime and punishment: an economic approach. Journal of Political Economy, v. 76, n. 2, mar. 1968.

CARDIA, N.; SCHIFFER, S. Violência e desigualdade social. Revista da Sociedade Brasileira para o Progresso da Ciência - SBPC -, ano 54, n. 1, jul. 2002.

CANO, I.; SANTOS, N. Violência letal, renda e desigualdade no Brasil. IPEA/ CESEC. Fórum de Debates: Criminalidade, Violência e Segurança Pública no Brasil. Uma Discussão sobre as Bases de Dados e Questões Metodológicas. $5^{\circ}$ Encontro, nov. 2000. Disponível em http://www.ipea.gov.br.

CERQUEIRA, D.; LOBÃO, W. Determinantes da criminalidade: uma resenha dos modelos teóricos e resultados empíricos. Rio de Janeiro: IPEA - Texto para Discussão n ${ }^{\circ}$ 956, jun. 2003a.

Condicionantes sociais, poder de polícia e o setor de produção criminal. Rio de Janeiro: IPEA - Texto para Discussão no 957, jun. $2003 \mathrm{~b}$.

Criminalidade: social versus polícia. Rio de Janeiro: IPEA - Texto para Discussão n ${ }^{\circ}$ 958, jun. 2003c.

CONJUNTURA CRIMINAL. Crime e desemprego. N. 1, maio 1998. Disponível em: http://www.conjunturacriminal.com.br, download realizado em set. 2001 .

FERNANDES, J.; PEREIRA, R. A criminalidade na região policial da Grande São Paulo sob a ótica da economia do crime. Disponível em: http://www.anpec.org.br/regional-fortaleza/, download realizado em mar. 2001.

GLAESER, E.; SACERDOTE, B.; SCHEINKMAN, J. Crime and social interactions. Quarterly Journal of Economics, v. 111, n. 2, maio 1996.

GREENBERG, D. (ed.). Crime and capitalism: readings in Marxist criminology. Filadélfia: Temple University, 1993.

GUJARATI, Damodar. Econometria básica. São Paulo: Makron Books, 1995.

HELLMAN, D.; ALPER, N. Economics of crime. $4^{\mathrm{a}}$ ed. Massachusets: Simon \& Schuster, 1993, caps. 3 e 4. 
HOFFMANN, R. Distribuição de renda: medidas de desigualdade e pobreza. São Paulo: EDUSP, 1998.

HUNT, E. K. História do pensamento econômico. $3^{\mathrm{a}}$ ed. Rio de Janeiro: Campus, 1985 , cap. 6.

JORGE, Marco A. Capacidade de absorção e qualidade do emprego no setor de serviços. 2000. Tese (Doutorado), apresentada à EAESP/FGV, São Paulo.

JORGE, M. A.; LEMOS, A.; SANTOS FILHO, E. A situação da segurança pública em Aracaju: causas da criminalidade e subsídios para o planejamento urbano. Aracaju, jul. 2002. Mimeografado.

KAHN, T. Os custos da violência: quanto se gasta ou deixa de ganhar por causa do crime no Estado de São Paulo. IPEA/CESEC. Fórum de Debates: Criminalidade, Violência e Segurança Pública no Brasil. Uma Discussão sobre as Bases de Dados e Questões Metodológicas. 5 Encontro, nov. 2000. Disponível em http://www.ipea.gov.br.

MASLOW, A. Motivation and personality. 2a ed. New York: Harper \& Row, 1970, caps. 4 e 7.

MELLO JORGE, M. H. Violência como problema de saúde pública. Revista da Sociedade Brasileira para o Progresso da Ciência - SBPC, ano 54, n. 1, jul. 2002.

MENDONÇA, M. Criminalidade e violência no Brasil: uma abordagem teórica e empírica. Revista Brasileira de Economia de Empresas, v. 2, n. 1, jan. 2002.

MENDONÇA, M.; LOUREIRO, P.; SACHSIDA, A. Interação social e crimes violentos: uma análise empírica a partir dos dados do Presídio da Papuda. Estudos Econômicos, v. 32, n. 4, p. 621-641, out./dez. 2002.

. Criminalidade e desigualdade social no Brasil. Rio de Janeiro: IPEA - Texto para Discussão n $\mathrm{n}^{\circ}$ 967, jul. 2003.

. Criminalidade e interação social. Rio de Janeiro: IPEA - Texto para Discussão no 968, jul. 2003.

MUSTARD, D. Reexamining criminal behavior: the importance of omitted variable bias. Review of Economics and Statistics, v. 85, n. 1, fev. 2003.

POCHMANN, M. Violência e emigração internacional na juventude. Revista da Sociedade Brasileira para o Progresso da Ciência - SBPC, ano 54, n. 1, jul. 2002.

SAH, R. Social osmosis and patterns of crime. Joumal of Political Economy, v. 99, n. 6, dez. 1991.

SAPORI, L. F.; WANDERLEY, C. B. A relação entre desemprego e violência na sociedade brasileira: entre o mito e a realidade. Konrad Adenauer Stiftung. A violência do cotidiano. São Paulo: Cadernos Adenauer, ano II, n. 1, 2001.

SARTORIS NETO, A. Homicídios na cidade de São Paulo: uma análise da causalidade e autocorrelação espaço-temporal. 2000. Tese (Doutorado), apresentada ao IPE-USP, São Paulo. 
SMITH, R.; EHRENBERG, R. A moderna economia do trabalho: teoria e política pública. $5^{\mathrm{a}}$ ed. São Paulo: Makron Books, 2000, cap. 9.

SOARES, L. E. Meu casaco de general. São Paulo: Cia. das Letras, 2000.

WENGER, M.; BONOMO, T. Crime, the crisis of capitalism and social revolution. In: GREENBERG, David (ed.), Crime and capitalism: readings in Marxist criminology. Filadélfia: Temple University, 1993.

\section{APENDICE}

O objetivo deste apêndice é mostrar que o modelo escolhido no trabalho está em consonância com os pressupostos do modelo de regressão linear múltipla. Os resultados dos testes são sintetizados na tabela abaixo.

\section{TABELA A.I - TESTES DAS HIPÓTESES DO MODELO DE REGRESSÃO LINE- AR MÚLTIPLA}

\begin{tabular}{|c|c|c|c|c|}
\hline Hipótese & Teste & Valor Calculado & Valor Tabelado & Resultado \\
\hline \multirow[t]{2}{*}{ Multicolinearidade } & \multirow{2}{*}{$\begin{array}{l}\text { FIV - Fator de } \\
\text { Inflamento da } \\
\text { Variância }\end{array}$} & DPATR $=1,249$ & & \multirow{2}{*}{$\begin{array}{l}\text { Ausência de } \\
\text { Multicolinearidade }\end{array}$} \\
\hline & & $\begin{array}{l}\text { DENS }=1,177 \\
\text { Esporte }=1,173 \\
\text { GINI }=1,031 \\
\text { Saúde }=1,065 \\
\text { FETA1 }=1,398 \\
\text { Média }=1,182\end{array}$ & 10 & \\
\hline \multirow[t]{2}{*}{ Heteroscedasticidade } & Goldfeld-Quandt & $\mathrm{Fc}=1,2312$ & Ftab $=3,44$ & \multirow{2}{*}{$\begin{array}{l}\text { Ausência de } \\
\text { Heteroscedasticidade }\end{array}$} \\
\hline & White & $X^{2}=26,52$ & $x^{2}=40,113$ & \\
\hline \multirow[t]{2}{*}{ Autocorrelação dos Resíduos } & Durbin-Watson & d.w. $=1,957$ & $\mathrm{dl}=1,097$ & Ausência de \\
\hline & & & $\mathrm{du}=1,884$ & Autocorrelação \\
\hline Normalidade dos Resíduos & Jarque-Bera & $\mathrm{JB}=4,8427$ & $\begin{array}{l}X^{2}(5 \%, 2)=5,99 \\
(p<0,05)\end{array}$ & Resíduos Normais \\
\hline
\end{tabular}

Os autores agradecem à Polícia Civil do Estado de Sergipe, em especial à equipe do CODEPE, à Polícia Militar do Estado de Sergipe, à Guarda Municipal de Aracaju, na pessoa dos capitães Henrique Rocha e Eduardo Henrique Santos e aos zelosos comentários dos pareceristas anônimas da revista. Também foram de extrema valia os apoios de Juan Carlos Cordovez (SEPLAN - Aracaju) e do prof. Arício Xavier de Oliveira (FGV/SP). O projeto foi financiado com recursos da Secretaria do Planejamento do Município de Aracaju. Obviamente, os erros remanescntes são de exclusiva responsabilidade dos autores.

(Recebido em outubro de 2003 . Aceito para publicação em abril de 2005). 